\title{
Jornalismo regional como mediador social: uma análise de conteúdo
}

\author{
Manuela Ghizzoni ${ }^{1}$
}

Resumo: O presente estudo se refere ao jornalismo regional do Vale do Rio do Peixe, localizado no meio-oeste catarinense. A pesquisa selecionou para uma análise os três principais veículos impressos da região em questão. Com o objetivo foi verificar se os meios de comunicação interioranos atuam como mediadores entre poder público e comunidade, a pesquisa se baseou nas teorias do jornalismo, construção social da realidade e análise de conteúdo. A partir da observação da produção jornalística nos veículos selecionados e uma análise quantitativa e qualitativa, foi possível estabelecer os processos jornalísticos contidos nos meios de comunicação locais, além de apontar suas características, fragilidades e potencialidades.

Palavras-chaves: Análise de conteúdo, jornalismo regional, jornalismo impresso catarinense

Abstract: The study presented here refers to the local journalism of the Vale do Rio do Peixe, situated in middle-west of Santa Catarina. The research selected for an analysis three main print media of the countryside. With the objective to verify if the selected local medias act as mediators between public power and community, the research is based on journalism theories, social construction of reality and content analysis. From the observation of journalistic production in the selected

\footnotetext{
${ }^{1}$ Graduada em Jornalismo pela Universidade Positivo e pós-graduanda em Gestão da Comunicação Organizacional pela FAE Business School. O presente artigo integra os estudos para a monografia: Jornalismo Regional Como Mediador Social: Uma Análise de conteúdo, orientada pela professora doutora Elza Aparecida de Oliveira Filha.
} 
vehicles and a quantitative and qualitative analysis, was possible to establish journalistic processes contained in the local media, while pointing out its features, weaknesses and potential.

Key words: Content analysis, local journalism, catarinense print journalism

\section{Introdução}

A proximidade com o público é uma das maiores vantagens dos jornais impressos regionais em comparação aos de circulação nacional. O conteúdo publicado nestes veículos frequentemente trata de assuntos que já são discutidos na vida cotidiana dos cidadãos, seja em conversas na praça ou discussão sobre política entre vizinhos. Com isso, a mídia regional adquire um grande poder de mobilização social para abordar reinvindicações e necessidades sociais dos leitores.

Apesar de importantes benefícios, a mídia local carrega uma imagem permeada por estereótipos e polêmicas, além de ser uma plataforma de comunicação pouco pesquisada em estudos científicos. Em função da carência de reflexão sobre os medias locais, este artigo se propõe a uma análise do conteúdo de três impressos do Vale do Rio do Peixe, situado no meio-oeste catarinense: Jornal Folha, A Coluna e Correio de Videira.

O Vale do Rio do Peixe está localizado no meio-oeste catarinense, uma das últimas regiões a serem colonizadas no estado. 
Hoje, a região mantém uma tradição agrícola e se caracteriza pela presença de municípios pouco populosos, criados e emancipados entre as décadas de 1930 e 1960. Atualmente, quatorze cidades integram a Associação dos Municípios do Alto Vale do Rio do Peixe, porém, apenas cinco serão abordadas neste trabalho devido a circulação dos mesmos veículos impressos de comunicação. Os municípios são: Arroio Trinta, Fraiburgo, Iomerê, Rio das Antas, Tangará e Videira, que juntos somam uma população de aproximadamente 97 mil habitantes ${ }^{2}$.

Sem estes meios de comunicação regionais, as comunidades da região seriam pouco abordadas nos veículos de porte estadual ou nacional. Por isso, necessitam da imprensa próxima para tornar públicas suas reinvindicações sociais, chamando assim a atenção dos governantes.

No entanto, o fator "proximidade" nem sempre é uma garantia de que os veículos regionais conseguem desempenhar o papel de mediador social entre governantes e sociedades. Diante disso, esse artigo se propõe a analisar se os meios de comunicação catarinenses são capazes de fornecer conteúdo relevante socialmente e oferecer espaço para o debate dos problemas locais.

Como hipóteses, a autora elenca a escassez de jornalistas e de recursos para investir no melhoramento da infraestrutura das redações,

\footnotetext{
${ }^{2}$ Dados da Associação dos Municípios do Alto Vale do Rio do Peixe. Disponível em: http://www.amarp.org.br. Acessado em 23/10/2013.
} 
o que pode gerar muitas vezes uma sobrecarga aos profissionais, ocasionando também uma grande dependência de informações oriundas de órgãos oficiais, pois não há tempo e nem espaço para ouvir os cidadãos. Outra hipótese é que, frequentemente, releases $^{3}$ na íntegra são encontrados em diversas editorias. Como consequência, o público se depara com matérias de cunho oficialista e conteúdo jornalístico sem qualquer relevância comunitária, gerando um distanciamento dos interesses da comunidade.

No decorrer do estudo, a autora acompanhou o processo de produção nas redações para identificar eventuais condicionantes do trabalho jornalístico, como o exemplo da falta de profissionais citado acima. Nestas visitas, foram realizadas entrevistas com proprietários dos veículos e, quando havia, com os jornalistas, para verificar como os profissionais avaliam o papel social dos meios de comunicação regionais.

Para efetuar um panorama do jornalismo regional, a pesquisa tem como base o papel do jornalismo na difusão de formas simbólicas, a midiatização na sociedade, a comunicação e sua influência na construção social da realidade, além de averiguar as fragilidades dos media locais.

\footnotetext{
${ }^{3}$ Termo técnico empregado para caracterizar um texto produzido de acordo com as estruturas do discurso jornalístico, com o intuito de informar os meios de comunicação sobre temas de interesse da organização. Segundo Rivaldo Chinem (2003), o objetivo é "subsidiar ou complementar o trabalho de levantamento de informação do repórter".
} 


\section{Jornalismo e Sociedade: breve histórico}

Mais do que reproduzir os fatos importantes do cotidiano, o jornalismo auxilia na construção da realidade e é por ela construído, sendo essencial na difusão cultural entre os indivíduos. Porém, foi com a consolidação da imprensa e o surgimento de grandes conglomerados midiáticos, a partir do século XIX, que a atividade jornalística começou a ser vista dessa maneira, dando início ao desenvolvimento dos meios de comunicação de massa.

O crescimento da alfabetização e a abolição dos impostos, unidos com avanços tecnológicos, influenciaram o desenvolvimento da indústria do jornal nos séculos XIX e XX, fase nomeada por Ciro Marcondes Filho (2000, p. 13) de "segundo jornalismo, o do jornal como grande empresa capitalista". Contudo, não foram apenas inovações tecnológicas que modificaram o "fazer jornalismo" da época. $\mathrm{Na}$ busca por agregar valor ao produto informativo, as empresas passaram a tornar o conteúdo jornalístico mais próximo dos leitores, com objetivo de atingir um público maior.

Aos poucos, os jornais se transformaram em grandes empreendimentos, consolidando os chamados "meios de comunicação em massa", capazes de alcançar centenas de milhares de leitores diariamente. Porém, o número de veículos impressos teve 
desenvolvimento inverso. Enquanto a circulação aumentava, a quantidade de jornais diminuía, simbolizando o monopólio da comunicação. Os grandes conglomerados auxiliaram na profissionalização das redações e no aumento da qualidade gráfica, no entanto, foram um revés para a informação regional e segmentada. Naturalmente, ocorreu o que Thompson (1998) chama de "globalização da comunicação". Agora, o conteúdo se voltava para o mundial.

A partir da metade do século XX, com o surgimento da televisão e das constantes inovações tecnológicas, o jornalismo mudou para sempre sua estrutura organizacional. Nas redações, foi estabelecida a produção em escala industrial, ao mesmo tempo em que se exigia - e ainda se demanda - ética, seriedade e objetividade dos profissionais durante o processo.

\section{Disseminação da Informação}

Não foi apenas a estrutura dos meios de comunicação que as novas tecnologias modificaram. A forma de se manter informado também se transformou. Hoje os fluxos de informações percorrem o globo terrestre numa velocidade jamais vista antes, e assumem formas e contextos cada vez mais sofisticados e condicionantes da vida humana. É possível dizer que a percepção que os cidadãos têm de si próprios foi alterada, assim como separada a interação social do local físico. Seja 
através de cartas ou mensagens eletrônicas, o contato humano não mais depende de ambiente e tempo comuns para ser efetivado.

Os campos sociais ${ }^{4}$ também sofreram influências. Ao invés de se fecharem para o que é exterior, agora se afetam mutuamente. "O campo dos media e os outros campos sociais ao mesmo tempo em que se autorefereciam, também se heterodeterminam" (TAVARES, 2007, p. 4). A mídia passou a ser necessária para que a sociedade veja "sentido nas continuidades da experiência e também para as intensidades da experiência" (idem).

Essa dependência dos meios de comunicação para que a sociedade compreenda os acontecimentos que a rodeia traz também a discussão sobre a influência da mídia na construção da realidade. Afinal, é ao jornalismo que se delega competência para recolher os acontecimentos e atribuir-lhes sentido, o que legitima a prática jornalística como uma das principais fontes de informações necessárias à compreensão do ambiente que circunda o real (LIMA, 2002).

A ideia de construção social da realidade é trazida inicialmente no campo da sociologia pelos autores Berger e Luckmann (1985). Para os estudiosos, a sociedade possui múltiplas realidades, entre as quais

\footnotetext{
${ }^{4}$ Termo empregado por Bourdieu (2002) ao se referir à interação entre os indivíduos que irão constituir determinadas relações. "[Campos sociais] é um universo relativamente autônomo de relações específicas e objetivas entre as posições ocupadas pelos seus agentes que determinam a forma de tais relações" (2002, p.66).
} 
predomina a vida cotidiana, dotada de sentido e regida por uma ordem social existente antes mesmo de o indivíduo entrar em cena.

A realidade da vida cotidiana é apreendida num contínuo de tipificações [falas, gestos e ações humanas], que vão se tornando progressivamente anônimas à medida que se distanciam do "aqui e agora" da situação face a face (...) A estrutura social é a soma dessas tipificações e dos padrões recorrentes de interação estabelecidos por meio delas. Assim sendo, a estrutura social é um elemento essencial da realidade da vida cotidiana (BERGER E LUCKMANN, 1985, p. 52).

Utilizando formas de linguagem aceitas em quase todas as sociedades - sejam as imagens de telejornais, o texto nos jornais impressos ou o diálogo nas emissoras de rádio - o jornalismo se afirma por ter um "papel socialmente legitimado e institucionalizado para construir uma realidade publicamente relevante" (ALSINA, 1993, p. 21) Tudo o que as outras instituições produzem em matéria de interpretações da realidade, os meios de comunicação selecionam, organizam (empacotam), transformam, na maioria das vezes no curso desse processo, e decidem sobre a forma da sua difusão (BERGER E LUCKMANN, 2004, p. 3).

\section{O Papel do Jornalismo Regional}

Mais do que estruturadores do cotidiano, os jornalistas, na hora em que definem as pautas, devem auxiliar para que a comunidade tenha 
seus anseios atendidos e conheça seus direitos. E é exatamente este um dos grandes trunfos do jornalismo regional: a função comunitária.

Apesar do interior do Brasil ter a presença cada vez mais constante da internet, ainda cabe ao jornalismo impresso o papel de principal informante dos cidadãos. Privilegiada pela proximidade com o público e os acontecimentos de âmbito local, a imprensa regional é essencial para facilitar o diálogo entre a população e o poder público. A importância do jornalismo regional é observada também em Santa Catarina. Caso os periódicos locais não existissem, a população catarinense estaria destinada a ter acesso a somente uma fonte de informação estadual: o Diário Catarinense, propriedade do conglomerado midiático Rede Brasil Sul (RBS).

Em relação às publicações locais, dados da Associação de Jornais do Interior de Santa Catarina (ADJORI-SC, 2012) mostram que existem trezentos títulos de jornais, das mais variadas periodicidades: diários, bissemanais, trissemanais, semanais, quinzenais e mensais. Nestes veículos, a tiragem representa aproximadamente 900 mil exemplares por mês.

A proximidade pode ser considerada o principal fator pelo qual o indivíduo escolhe ler um periódico local. Devido à necessidade de se socializar no âmbito em que vive, o cidadão anseia por algo com o qual se reconheça como membro da sociedade (CANDIDO, 2005, p. 04). Assim, por meio das notícias, o leitor se sente parte da comunidade, 
sendo capaz de efetuar uma reflexão crítica sobre os problemas ao seu redor o que possibilita também exercer um papel na construção social da realidade.

Conforme relatado acima, a imprensa regional é essencial em aspectos políticos, sociais e culturais de uma comunidade, porém não se pode "endeusar" este segmento. É preciso compreender que o jornalismo regional não está imune às práticas mercadológicas, por isso, torna-se importante estudá-lo profundamente para entender suas especificidades e fragilidades, com o intuito de tornar a prática jornalística no interior cada vez mais profissional e comprometida com a sociedade.

\section{Análise de Conteúdo}

O objeto de estudo da atual pesquisa são as reportagens publicadas em três jornais da região do Vale do Rio do Peixe, objetivando a verificação das hipóteses levantadas a respeito da mídia impressa catarinense. Para analisar e compreender de forma eficaz as reportagens existentes nos veículos escolhidos é necessário observar os elementos por trás da produção jornalística.

Partindo do pressuposto abordado anteriormente de que os meios de comunicação constroem a realidade e são por ela construídos, 
o entendimento das práticas que envolvem o newsmaking ${ }^{5}$ permitem compreender o jornalismo "na contemporaneidade e o modo como ele se insere e se relaciona com as mudanças sociais e culturais em curso" (STRELOW, 2010, p. 47).

Por causa de suas múltiplas faces, a análise de um jornal é um procedimento complexo e delicado. Dessa forma, a autora desta pesquisa optou por realizar uma investigação do emissor da informação, possibilitando assim aprofundar os elementos que envolvem desde o momento da escolha da informação a ser apurada até os valores que influenciam na publicação de determinada reportagem.

A principal influência desta pesquisa é a Análise Global de Processos Jornalísticos (AGPJ), proposta inicialmente por Aline Strelow e que busca compreender quatro momentos distintos: contexto sócio-histórico-cultural; produção jornalística; textos (reportagens); leituras e retornos.

Porém, como afirmado anteriormente, o enfoque deste estudo está apenas nas práticas jornalísticas relacionadas ao emissor do conteúdo, desta maneira, as duas etapas conhecidas como Análise de

\footnotetext{
${ }^{5}$ Trata-se de uma teoria que tem como objetivo estudar a notícia, analisando como os meios de comunicação selecionam a matéria-prima, fatos e todos os critérios estabelecidos pelos veículos para essas ações. Os teóricos do newsmaking acreditam que estes critérios utilizados para a estruturação das notícias são "resultado das produções realizadas pelos meios, da cultura dos próprios jornalistas que escolhem o que é relevante ou não para apresentar a sociedade". (MELZ, 2012, pag. 2).
} 
Leituras e Retornos não serão abrangidas, pois se referem aos leitores dos jornais, ou seja, à recepção do material jornalístico.

Nesta pesquisa, foram analisadas, pelo viés qualitativo, três reportagens oriundas de cada veículo abordado durante o trabalho, totalizando nove notícias. Todas as matérias pertencem ao mês de abril, época escolhida devido à proximidade das eleições municipais de 2012, que ocorreram no mês de outubro.

Para a escolha das notícias, optou-se por aquelas que abordam temas de interesse da comunidade. A partir destes temas, foi possível realizar uma verificação aprofundada das hipóteses, de forma a identificar se os veículos analisados proporcionam espaço para debate, discutem problemas e situações e se os próprios cidadãos, beneficiários destas melhorias, fazem parte destas discussões.

Em sua análise de conteúdo de jornais regionais paulistas, Ribeiro (2004, p. 109) propôs uma definição de categoria que será utilizada, com algumas alterações, nesta pesquisa, a qual engloba: tema de interesse público, intenções, problemas e situações discutidos, soluções e alternativas apresentadas, origem das informações, produtor da reportagem, entrevistas realizadas e espaço destinado à reportagem. 


\subsection{Imprensa do Meio-Oeste Catarinense}

A evolução e consolidação da imprensa no interior só são possíveis em virtude da sua importância para a comunidade. Preocupados cada vez mais em aprimorar a qualidade técnica e de conteúdo, os jornais regionais contribuem ao investigar e abordar temas pertinentes ao público local. Contudo, os profissionais ainda estão inseridos em um cenário significativamente agrícola.

Com o intuito de conhecer melhor as redações regionais, a autora desta pesquisa efetuou visitas às sedes dos veículos analisados e conversou com os jornalistas presentes, além dos proprietários. Foi aprofundada questões referentes a remuneração, satisfação no trabalho e questões envolvendo o processo do newsmaking, valores-notícias e conflitos que podem existir com empresários e políticos da região. Os jornais analisados para esta pesquisa foram: A Coluna, Correio de Videira e Folha de Videira, ambos com sede em Videira e formato tabloide.

\subsubsection{Jornal Folha}

Criado há quatro anos, o Jornal Folha se diferencia por ser o único com circulação bissemanal nas cidades de Videira, Fraiburgo, Iomerê e Tangará. Disponível aos sábados e terças-feiras, a publicação 
possui tiragem de dois mil exemplares. É o jornal que se mostrou mais completo na questão profissional e estrutural. A equipe responsável pela produção é formada por dois jornalistas com formação acadêmica superior em Jornalismo, um editor-chefe com habilitação em Relações Públicas e um diagramador. Os jornalistas possuem remuneração média de $\mathrm{R} \$ 2.000$

Os recursos para sustentar a significativa estrutura não são oriundos apenas da comercialização de anúncios e existência de assinantes. Desde a sua criação, o Jornal Folha é mantido com recursos próprios de seu proprietário, o que mostra uma fragilidade dos veículos regionais e dificuldade em obter lucro com a informação. Os investimentos são provenientes de outras empresas, especialmente relacionadas ao comércio imobiliário videirense. Em entrevista, o editor-chefe - nomeado aqui de EC1 - explica que os lucros obtidos são reinvestidos no próprio veículo.

Nós pertencemos a um grupo de empresas que não depende do meio jornal para sobreviver. Somos um grupo empresarial que trabalha em cinco ramos de atividades, como a construção civil e a imobiliária. A Folha existe há quatro anos, relativamente nova, e hoje todos os lucros adquiridos no jornal são reinvestidos. A consequência disso é uma sede que nos dá um knowhow de jornal de grandes centros $(\mathrm{EC} 1,2012)$.

\footnotetext{
${ }^{6}$ EC1 refere-se ao editor-chefe do Jornal Folha, nomeação utilizada para manter a privacidade do entrevistado.
} 
A autoria de conteúdo é outra característica deste meio de comunicação. Grande parte das reportagens é realizada dentro da sua redação. Apesar da disponibilidade de tempo e recursos para "correr atrás dos fatos", os profissionais da Folha se deparam com um dos maiores problemas relatados pelos jornalistas locais: a escassez de assuntos factuais. Esse cenário faz com que o veículo necessite recorrer às agências de notícias, especialmente nas edições de terças-feiras.

Em um total de 126 reportagens avaliadas, e publicadas no mês de abril de 2012, verificou-se a predominância de textos com temática esportiva $(23,02 \%)$, seguido de política $(19,84)$ e polícia $(12,70 \%)$. Na área de esporte, a ênfase é para os campeonatos de futsal da região. Já a editoria de política aborda principalmente ocorrências da Câmara Municipal de Videira, enquanto a editoria de polícia traz acidentes de trânsito e assaltos.

Em relação à análise de conteúdo das três reportagens, constatou-se que todas as discussões contidas no Jornal Folha se referiam a temas locais e diziam respeito ao assunto Educação.

Na primeira edição de abril (07/04), a reportagem "Secretaria de Educação implanta Escola em Tempo integral" desperta o interesse da comunidade videirense ao abordar a implantação da primeira escola em tempo integral do município. No texto, os profissionais procuraram mostrar os benefícios a longo prazo que esta forma educacional traz para a população. 
Como a regra dentro do jornal Folha é buscar sempre as autoridades, a entrevista com o Prefeito videirense é somada com outras três vozes oficiais, mas, diferenciando-se de outras matérias, esta procurou entrevistar um cidadão, no caso a mãe de um estudante. A grande quantidade de entrevistados possibilitou o aprofundamento do assunto.

Contudo, observa-se que as reportagens referentes ao tema educação do mês de abril surgiram apenas por estarem relacionadas ao poder público. Isso mostra a capacidade de agendamento que eventos exteriores têm na rotina do veículo em questão, o que pode ser observado pelas outras duas reportagens que abordam o segmento, referentes aos dias 21 e 28 de abril. Elas foram elaboradas devido à possibilidade dos professores de escolas públicas entrarem em greve.

Um fato marcante encontrado na abordagem desta situação grevista foi a parcialidade da informação. Em ambas as reportagens, houve a predominância da voz oficial, através de entrevistas com o Secretário Municipal da Educação e Prefeito, ou seja, figuras públicas responsáveis por proteger a imagem da Prefeitura de Videira.

$\mathrm{Na}$ reportagem do dia 21 de abril, período em que a ocorrência da greve era certa na região, o veículo mostrou uma tentativa de imparcialidade ao entrevistar o Presidente do Sindicato, além de estampar sua fotografia durante um discurso. Entretanto, a voz do "antagonista" da situação foi minimizada com duas entrevistas 
favoráveis ao poder público: secretário municipal da educação e a gerente regional de educação.

Mesmo que um dos intuitos dos profissionais seja agregar conhecimento ao leitor, o jornal falha ao não apresentar soluções possíveis para o entrave grevista, o que, em parte, distancia o leitor dos problemas e faz com que ele apenas reflita sobre o quanto a situação poderá atrapalhar o seu próprio dia a dia, e não a qualidade da educação pública.

\subsubsection{A Coluna}

Há dez anos, o jornal A Coluna circula semanalmente nas cidades de Videira e Fraiburgo, sendo publicado todas as sextas-feiras. A equipe é formada por um diagramador e um jornalista - com formação acadêmica em jornalismo - responsável pela produção de conteúdo. Este único profissional de comunicação possui salário mensal de mil reais.

Apesar da preocupação em contratar profissionais com formação acadêmica, o tamanho bastante restrito da equipe jornalística faz com que a qualidade do conteúdo muitas vezes seja prejudicada. De acordo com o jornalista - nomeado aqui J1 -, ele se sente sobrecarregado na hora da produção das matérias. "Nós temos uma boa estrutura, mas eu acho que precisaria de mais uma pessoa para me ajudar. Mesmo sendo 
semanal, é um jornal grande e muitas vezes eu não dou conta de aprofundar as matérias, de fazer um trabalho bem feito" (J1, 2012).

O jornalista do A Coluna possui suporte do editor-chefe e também proprietário do veículo. Além de ocupar as duas funções, o dono atua na área comercial do impresso, prática comum encontrada nos meios de comunicação regionais. De acordo com o proprietário do veículo, nomeado aqui de EC2, excluindo-se os assinantes, toda a renda financeira do jornal é oriunda de publicidades legais e anunciantes de comércios e indústrias da região.

A proximidade do comercial com a redação pode trazer grandes prejuízos, especialmente se o anunciante deseja evitar que um acontecimento que possa denegri-lo se torne de conhecimento público. EC2 explica que já passou por inúmeras situações como esta especialmente com empresários da região, mas tendo consciência da sua função social, optou pela defesa do cidadão.

Você tem sempre a retaliação, o pessoal corta seu comercial, cancela a assinatura. A gente fez uma matéria da [indústria alimentícia], falando sobre a mixaria que a empresa paga pelos frangos daqui e só conseguimos que eles não retirassem os seus anúncios porque ameaçamos não consumir mais os produtos e contar como a fábrica produz os frangos com o suor dos trabalhadores videirenses. Com essa ameaça, evitamos que eles não retirassem o anúncio, pois caso isso acontecesse, provavelmente "quebraria" o jornal (EC2, 2012). 
Novamente as editorias esportes (24\%) e polícia (24\%) lideram na quantidade de temas publicados. Logo em seguida, encontram-se os assuntos de maior interesse da comunidade como utilidade pública $(10,67 \%)$, educação $(9,33 \%)$ e saúde pública $(6,67 \%)$. As reportagens publicitárias, por exemplo, sobre lançamento de um novo automóvel, encontram-se em último lugar (1,33\%), empatadas com religião, trânsito e turismo.

Neste veículo, para a análise de conteúdo, optou-se por escolher as reportagens incluídas na editoria "Especial", responsável por trazer semanalmente assuntos não necessariamente factuais, mas que podem influenciar o cotidiano dos leitores. No mês de abril, não houve repetição de temas, sendo abordados: saúde pública, trânsito e educação. Em apenas uma das reportagens analisadas, o jornal se distanciou da característica local.

Em "Quase metade dos brasileiros está acima do peso", a autora considerou que não houve interesse local, e sim geral, pois a reportagem aborda a situação da obesidade em âmbito nacional. Uma das falhas encontradas foi a falta de informações sobre a situação da obesidade nos municípios onde A Coluna circula ou até mesmo no estado de Santa Catarina. Todas as informações são ancoradas na voz especializada de uma nutricionista videirense. $\mathrm{O}$ restante das informações foram obtidos por meio de dados oficiais divulgados pelo Ministério da Saúde. 
A pequena quantidade de entrevistas está presente também na reportagem "Em três meses, Videira registrou 232 acidentes de trânsito". Ao se utilizar a voz oficial do Capitão da Polícia Militar de Videira, o repórter busca as causas do aumento no número de acidentes e as ações que estão sendo efetuadas pelo poder público para mudar esta situação.

Mesmo com a possibilidade de ser um tema de certa forma humanizado, o veículo preferiu dar ênfase a estatísticas e dados técnicos. Ao contrário da matéria anterior, esta é majoritariamente local, pois aborda a questão do trânsito apenas em Videira, não sendo apresentados dados sobre o Brasil ou outros municípios.

Através da matéria, o veículo consegue fazer uma conexão importante entre poder público e população. Ao mesmo tempo em que são mostradas as causas dos acidentes, as falas oficiais utilizadas evidenciam o que o órgão está fazendo atualmente e pedem a cooperação e conscientização dos leitores na luta contra a violência no trânsito.

Em "Novo plano de carreira do magistério é aprovado no município", A Coluna novamente aproxima o leitor do poder público ao evidenciar a situação dos professores da rede pública no município de Fraiburgo. O texto explica que os próprios vereadores vetaram o aumento salarial dos educadores e em seguida, destaca a fala do prefeito municipal. "Ao contrário de quase todos os municípios e estados do 
país que alegam não poder cumprir o piso nacional do magistério, Fraiburgo, através do Poder Executivo, quer e pode cumprir o piso nacional no valor de $\mathrm{R} \$ 1.451,00$, contudo, fica proibido por decisão dos vereadores que votaram contra o projeto."

No momento em que mostra ao leitor os bastidores da política municipal - no caso o veto dos vereadores -, o jornal possibilita que os cidadãos se tornem informados e possam cobrar seus direitos e também direito dos profissionais responsáveis por educar durante uma vida inteira seus filhos.

\subsubsection{Correio de Videira}

É um dos jornais mais antigos e tradicionais do Vale do Rio do Peixe, com 19 anos de existência. Circula semanalmente, sempre aos sábados, nos municípios de Videira, Rio das Antas, Fraiburgo, Tangará e Arroio Trinta. Ao contrário dos outros veículos analisados, o Correio de Videira é o único impresso sem a presença de um jornalista com formação superior acadêmica. $\mathrm{O}$ editor-chefe do jornal - nomeado nesta pesquisa de EC3 - é o único profissional presente na redação, atuando na produção e edição de reportagens.

Com 35 anos de experiência na profissão, EC3 é um dos jornalistas mais antigos do município e pode ser considerado o gatekeeper $^{7}$ do veículo. Na hora de apurar uma matéria, o profissional

7 Desenvolvida em meados da década de 1950, a teoria do Gatekeeper busca identificar os responsáveis por filtrarem a seleção das notícias. 
leva em conta os interesses da comunidade. "Se eu tenho 32 páginas de notícias locais, escolherei elas. Essa é a tendência” (EC3, 2012).

O jornalista acima é responsável também pelo setor comercial do Correio de Videira. A principal fonte de renda para manter o veículo é proveniente de anúncios. Pelo fato do único jornalista disponível ser encarregado pela redação e venda destes anúncios, o meio de comunicação acaba se tornando consideravelmente dependente de matérias oriundas de assessorias de imprensa de órgãos oficiais e agências de notícias, especialmente na área de variedades.

Esta característica tem como consequência a escassez de reportagens voltadas aos problemas e situações vivenciadas nos municípios de circulação do jornal. Os assuntos mais abordados seguem a mesma tendência que os veículos anteriores, ou seja, polícia $(28,13 \%)$ e esporte $(18,75 \%)$.

Porém, algo que deve ser enfatizado nesta investigação é a grande presença de informes comerciais $(15,63 \%)$ em relação a temas como educação $(12,50 \%)$ e saúde pública $(6,25)$. Apenas na edição do dia 14 de abril, foram constatadas duas informes comerciais: uma sobre um novo automóvel da revenda anunciante e outra sobre a feira de carros também desta mesma loja.

Este modelo de notícia unido com informações provenientes de assessorias de comunicação, escassez de tempo e falta de jornalistas, influencia não apenas o conteúdo, mas as fontes utilizadas no jornal. $\mathrm{O}$ 
Correio de Videira foi o veículo que usou uma variedade menor de fontes. Verificou-se que, entre 35 matérias, 30 utilizaram a voz oficial. Os personagens testemunhais foram utilizados, em grande parte, na editoria geral e Polícia, já os institucionais se referem às vozes contidas em reportagens publicitárias.

Para a análise de conteúdo deste veículo, todos os assuntos contidos nas notícias analisadas são de interesse local, pois falam de situações referentes à microrregião de Videira.

Na primeira matéria do mês de abril, intitulada "TV Câmara de Videira está no ar", o veículo explica à população a nova ferramenta digital que auxiliará as pessoas a monitorarem o poder legislativo municipal. O texto tenta ao máximo mostrar como este objeto inédito na cidade pode ser importante na cidadania. "De agora em diante, a população poderá assistir as sessões ao vivo pela internet, com a comodidade de não precisar sair de casa. As gravações das sessões também ficam armazenadas e podem ser acessadas após as suas realizações". Ao fazer uso da expressão "a comodidade de não precisar sair de casa", o veículo evidencia as facilidades que a TV Câmara agrega aos interessados.

Mesmo obtida por meio de release oficial divulgado pela assessoria do órgão legislativo, a notícia consegue cumprir seu papel de informar a população sobre o que ocorre no âmbito político do município. 
A assessoria de imprensa da Câmara Municipal de Videira também foi responsável por produzir a segunda matéria da editoria de Política "Alunos do Cepar participam de sessão". Nesta reportagem, foi destacado o projeto integrado por estudantes da rede pública de ensino, onde os participantes percorreram bairros do município com o intuito de verificar como está a conservação do patrimônio público.

O jornalista teve preocupação em entrevistar os alunos que participaram do projeto, porém, suas falas foram pouco utilizadas. O presidente da Câmara Municipal se tornou a voz principal da notícia, presente em quase todos os momentos do texto. As informações complementares da matéria foram adquiridas através da apresentação dos estudantes.

Diferenciando-se de todas as notícias analisadas, a reportagem "Produtores independentes reclamam do baixo preço do suíno vivo", do dia 14 de abril, se mostrou uma maneira efetiva de dar voz aos produtores locais, que há anos vêm sendo explorados pelas grandes empresas alimentícias.

A apuração da informação coube ao editor-chefe do Correio de Videira, que visitou o interior do Vale do Rio do Peixe em busca de testemunhas que confirmassem o mau momento vivido pelos suinocultores, especialmente pertencentes aos de Salto Veloso e Arroio Trinta, locais onde atividade é uma das únicas fontes de renda das famílias. 
Apesar dos personagens não serem identificados, possivelmente por receio de retaliações, houve uma quantidade considerável de entrevistados, totalizando três fontes testemunhais. Todos cederam informações importantes para comprovar a situação, como no trecho: “Os frigoríficos estão pagando em média $\mathrm{R} \$ 1.70$ pelo quilo do animal vivo, ficando bem abaixo do preço de custo, que está em torno de $\mathrm{R} \$$ 2.70".

Na matéria correlata são apresentadas algumas soluções para o problema, como a necessidade da realização de uma campanha nacional em prol do consumo de carne suína, sugestão dada por um entrevistado. "O consumo de carne suína é baixo, até por falta de oferta do produto nos supermercados".

Contudo, apesar de ter sido uma ferramenta importante na defesa dos interesses econômicos da população, reportagens como estas não são comumente encontradas no Correio do Povo. Falta ao veículo a busca por aquilo que os órgãos oficiais não vêem necessidade - ou não gostariam - de tornar público. Apesar de facilitar a rotina dos jornalistas, o excesso de informações oriundas de assessorias de imprensa acaba por prejudicar a qualidade do conteúdo e padronizar os veículos da cidade, evitando que os leitores tenham acesso à informações diferenciadas. 


\section{Considerações finais}

O estudo "Jornalismo Regional como Mediador Social: uma análise de conteúdo" resultou em algumas considerações relevantes a respeito da comunicação no Vale do Rio do Peixe, constituído por localidades pouco representadas pelos impressos estaduais de grande porte. Com esta pesquisa, foi possível minimizar estigmas referentes ao conteúdo e à profissionalização em pequenos jornais.

Através da análise de conteúdo, constatou-se que há uma tentativa constante de se distanciar a opinião de proprietários do conteúdo jornalístico restante. Isso se dá especialmente na distinção entre o que são textos de opinião, presentes geralmente nas primeiras duas páginas, e reportagens propriamente ditas.

Em dois veículos, Jornal Folha e A Coluna, o "local" se mostrou o principal valor-notícia contido neste conteúdo jornalístico. Entretanto, mesmo contendo fatos locais, os veículos falham em trazer a voz do cidadão para dentro das reportagens. Em todos os meios de comunicação analisados, a pesquisadora concluiu que há predomínio do "oficialismo", uma das maiores críticas atualmente aos jornais do interior. Grande parte das matérias foi pautada por assessorias de órgãos oficiais e traz como fontes únicas, as entrevistas com prefeitos e secretários municipais. Como consequência, há a presença de 
reportagens sem debates sociais e indivíduos que mostrem o outro lado da história.

Em relação à profissionalização dos veículos, encontrou-se uma imensa diferença entre todos os analisados. O Jornal Folha se mostrou o mais preparado estruturalmente e profissionalmente, contendo dois jornalistas com formação acadêmica superior.

A equipe considerada de tamanho satisfatório se traduz na quantidade de reportagens e periodicidade, sendo o único impresso bissemanal da região, responsável por trazer novas informações para os leitores no meio da semana, neste caso, todas as terças-feiras. O Jornal Folha é também o que mais produz conteúdo, publicando apenas no mês de abril 126 reportagens, contra 35 do Correio de Videira e 60 do A Coluna.

Apesar de uma equipe restrita, A Coluna também evidenciou preocupação com a qualidade dos profissionais, contudo, possui apenas um jornalista formado para produzir conteúdo de nove editorias fixas. O fato do proprietário atuar também como editor-chefe é outro elemento que deve ganhar atenção, pois é uma prática considerada comum nos veículos da região, o que pode ser comprovado também pela análise do Correio de Videira, onde o diretor e editor-chefe são a mesma figura.

Conclui-se desta análise que há uma crescente tentativa de profissionalização e melhora do conteúdo, exemplo encontrado nas 
reportagens especiais pertencentes ao jornal A Coluna, porém, os veículos falham em fazer a população ser ouvida.

A prática jornalística não deve ser pensada apenas como uma narrativa superficial de fatos, e sim, deve fornecer informações diferenciadas para que o público possa efetuar suas reflexões e interpretação das situações ali apresentadas.

Por buscar apenas a voz oficial, os jornais analisados não são capazes de efetuar uma mediação eficiente entre poder público e comunidade. Há apenas o relato semanal das ações do poder público. Para conseguir fazer parte da construção social de Videira e região, os veículos necessitam começar a buscar pelos dois lados da notícia, ouvir o que o cidadão tem a dizer, por exemplo, sobre a nova unidade de saúde de seu município.

Pode-se se dizer que hoje os veículos do Vale do Rio do Peixe se encontram reféns das assessorias de comunicação, além de existir um comodismo em entrevistar políticos, pois suas falas já são padronizadas e prontas para serem inseridas no corpo do texto. Com o cidadão é diferente, é preciso uma abordagem mais humanizada, um tratamento das informações contidas nas entrevistas, porém, estes procedimentos levam tempo e, consequentemente, recursos financeiros. 


\section{Referências}

ADJORI-SC. Dados jornais regionais de Santa Catarina [mensagem pessoal]. Mensagem recebida por <manuelaghizzoni@hotmail.com> em 05 de junho de 2012.

ALSINA, Miguel Rodrigo. La construcción de la noticia. Barcelona: Edicioneis Paidós, 1993. 166 p.

BERGER, Peter L; LUCKMANN, Thomas. A construção social da realidade: tratado de sociologia do conhecimento. Petrópolis: Vozes, 1985. $247 \mathrm{p}$.

BERGER, Peter L; LUCKMANN, Thomas. Modernidade Pluralismo e Crise de Sentido. Petrópolis: Editora Vozes, 2004. 96 p.

BOURDIEU, Pierre. O poder simbólico. Rio de Janeiro: Bertrand Brasil, 2002. 311 p.

CANDIDO, Vanessa Aparecida. (2005) O jornalismo impresso como instrumento de resgate e construção da história regional. Disponível em: <http://encipecom.metodista.br/mediawiki/images/c/c3/GT1-_02-

_O_jornalismo_impresso-_Vanessa.pdf $>$ (acesso em 06 de junho de 2012)

CHINEM, Rivaldo. Assessoria de imprensa: como fazer. São Paulo: Summus, 2003. 184 p.

EC1. Entrevista concedida a Manuela Ghizzoni em: 05/07/2012. Videira.

EC2. Entrevista concedida a Manuela Ghizzoni em: 04/07/2012. Videira. 
EC3. Entrevista concedida a Manuela Ghizzoni em: 08/07/2012. Videira.

J1. Entrevista concedida a Manuela Ghizzoni em: 04/07/2012. Videira.

LIMA, Marcus Assis. (2002) Jornalismo Futuros. Disponível em: <http://www.bocc.ubi.pt/pag/lima-marcus-assis-jornalismo-futuros.pdf> (acesso em 22 de maio de 2012)

MARCONDES FILHO, Ciro. A saga dos cães perdidos. São Paulo: Hacker, 2000. $171 \mathrm{p}$.

MELZ, Talita. (2012) Abordagem dos conceitos e critérios do newsmaking nas teorias do jornalismo: valores-notícias substantivos. Disponível em: <http://www.intercom.org.br/papers/regionais/norte2012/resumos/R290081-1.pdf> (acesso em 01/11/2013)

RIBEIRO, Juliana. (2004) Jornalismo Regional e Construção da cidadania. Disponível em: <http://www.bocc.ubi.pt/pag/ribeiro-julianajornalismo-regional- construcao-cidadania.pdf $>$ (acesso em 22 de maio de 2012).

STRELOW, Aline. Análise Global de Processos Jornalísticos: uma proposta metodológica. Porto Alegre: EdiPUCRS, 2010. 76 p.

TAVARES, Frederico de Mello Brandão. (2007) Quando o jornalismo encontra a auto-ajuda: midiatização e ressemantização do discurso noticioso. Disponível em: <http://projeto.unisinos.br/midiaticom/conteudo/artigos/2007/artigos_ex ternos/Artigo_FredericoTavares.pdf $>$ (acesso em 23 de maio de 2012)

TRAQUINA, Nelson. O estudo do jornalismo no século XX. São Leopoldo: Editora Unisinos, 2001. 220 p. 
THOMPSON, John B. A mídia e a modernidade: uma teoría social da mídia. Petrópolis:

Vozes, 1998.

261

p. 